Research Article

\title{
Comparison of Pharmacokinetics and Tissue Distribution Characteristics of Three Diterpenoid Esters in Crude and Prepared Semen Euphorbiae
}

\author{
Hui-Nan Wang $\left(\mathbb{D},{ }^{1}\right.$ Pei-Hua Wang $\mathbb{D}^{1},{ }^{1}$ Zi-Ye Yang $\left(\mathbb{D},{ }^{1}\right.$ Gui-Mei Zhang $\mathbb{D}^{1}$ \\ Meng-Yu Chen $\mathbb{D},{ }^{1}$ Ming-Rui Jiang ${ }^{\mathbb{D}},{ }^{1}$ Zhu-Zhu Yue $\mathbb{D},{ }^{1}$ Zhi-Cheng Wang $\mathbb{D}^{1}{ }^{1}$ \\ Jing-Qiu Zhang $\mathbb{D}^{1},{ }^{1}$ Yan-Hua Cao $\mathbb{D}^{2},{ }^{2}$ Hong An $\mathbb{D}^{1},{ }^{1}$ and Ying-Zi Wang $\mathbb{D}^{1}$ \\ ${ }^{1}$ School of Chinese Materia Medica, Beijing University of Chinese Medicine, Beijing 102488, China \\ ${ }^{2}$ Department of Pharmacy, Shandong Provincial Hospital Affiliated To Shandong First Medical University, Jinan 250021, China
}

Correspondence should be addressed to Ying-Zi Wang; wangyzi@sina.com

Received 29 April 2021; Accepted 7 August 2021; Published 17 August 2021

Academic Editor: Josué de Moraes

Copyright (c) 2021 Hui-Nan Wang et al. This is an open access article distributed under the Creative Commons Attribution License, which permits unrestricted use, distribution, and reproduction in any medium, provided the original work is properly cited.

\begin{abstract}
Background. Semen Euphorbiae (SE) and Semen Euphorbiae Pulveratum (SEP) have a long history of medicinal use. SEP is the processed product of SE; both ancient and modern studies have shown that SEP has a lower toxicity compared to SE. To clarify the influence of processing on the pharmacological properties of SE and SEP, a study was carried out to compare the pharmacokinetics and distribution characteristics of three active compounds after oral administration of SE and SEP extracts. Methods. A UPLC-MS/MS method was established to simultaneously determine the contents of Euphorbia factors $\mathrm{L}_{1}, \mathrm{~L}_{2}$, and $\mathrm{L}_{3}$ in rat plasma and mouse tissues after an oral administration of crude and processed SE with approximately the same dosage. Plasma and heart, liver, spleen, lung, kidney, and colon tissue samples were treated with ethyl acetate and separated by gradient elution on a C18 column with a mobile phase of $0.1 \%$ formic acid and methanol. Results. The established method had good selectivity, linear range, accuracy, precision, stability, matrix effect, and extraction recovery. The area under the concentration time curve, time to maximum concentration, maximum concentration, half-life of elimination, and mean retention time of plasma samples in SEPtreated group decreased, and the clearance in SEP-treated group increased. Moreover, the active component concentrations in colon, liver, and kidney tissues were more followed by those in the heart, lungs, and spleen. Conclusion. These results indicate that the processing could influence the pharmacokinetics and tissue distribution of Euphorbia factors $\mathrm{L}_{1}, \mathrm{~L}_{2}$, and $\mathrm{L}_{3}$ after oral administration of crude and processed SE. The data obtained may lay a foundation for the clinical use of SE and for further study on the processing mechanism of SE.
\end{abstract}

\section{Introduction}

Semen Euphorbiae (SE) is the dried mature seed of Euphorbia lathyris L., which is a kind of traditional Chinese medicine (TCM) that is widely used in the treatment of hydroncus, ascites, anuria, astriction, menostasis, and scabies $[1,2]$. Modern pharmacological studies have shown that SE has several pharmacological activities, including laxative effects, antitumor effects, reversal of tumor multidrug resistance effects, anti-inflammatory activity, and whitening effects [3-5]. However, its toxicity greatly limits its further development and clinical application. Semen Euphorbiae Pulveratum (SEP) is the processed product of SE, prepared by removing the oil from the SE; both ancient and modern studies have shown that SEP has a lower toxicity compared to $\mathrm{SE}[6,7]$. Considering that processing can change the content of the active ingredients and affect their pharmacokinetics $[8,9]$, it is necessary to study the pharmacokinetics differences of the active components of SE before and after processing. 
Phytochemical investigation reveals that SE contains diterpenoids, sterols, coumarins, flavonoids, volatile oils, fatty oils, and many other chemical components [5]. Diterpene esters are the primary and active components of $\mathrm{SE}$, among which Euphorbia factors $\mathrm{L}_{1}, \mathrm{~L}_{2}$, and $\mathrm{L}_{3}$ are three most major active diterpene esters [10]. These three components are found in relatively high amounts and have significant pharmacological effects such as laxative, antiinflammatory, and antitumor effects [11-13].

Pharmacokinetic studies are helpful to explain and predict the absorption, distribution, and excretion of active ingredients in vivo $[14,15]$. HPLC has been used to study the pharmacokinetics of Euphorbia factor $\mathrm{L}_{1}$ [16], while LC-MS/ MS method has been used to determine the pharmacokinetic properties of three diterpene esters after oral administration of the SE extract [17]. However, these methods exist with some limitations, containing low sensitivity, long running time, large sample size, and complex sample pretreatment [18]. Thus, it is necessary to establish a sensitive and quantitative method to simultaneously determine the differences in the concentration and distribution of Euphorbia factors $\mathrm{L}_{1}, \mathrm{~L}_{2}$, and $\mathrm{L}_{3}$ in crude and prepared $\mathrm{SE}$ in rat plasma and mouse tissues.

Our study reports a rapid and sensitive UPLC-MS/MS method to simultaneously determine the contents of Euphorbia factors $\mathrm{L}_{1}, \mathrm{~L}_{2}$, and $\mathrm{L}_{3}$ in rat plasma and heart, liver, spleen, lung, kidney, and intestinal tissues of mice. This method has been applied to determine the pharmacokinetics and tissue distribution characteristics of crude SE and its processed products in order to clarify the influence of processing on the pharmacological properties of SE and to lay a foundation for further study of SE.

\section{Materials and Methods}

2.1. Chemicals and Materials. SE was bought from Anhui Bozhou Huqiao TCM Herbal Pieces plant in Jiangxi Province, China (Lot No. 1203070692), and identified by Professor Chunshen Liu from the School of Chinese Materia Medica, Beijing University of Chinese Medicine. Petroleum ether extracts of SE and SEP were made in the laboratory. The reference standards of Euphorbia factor $\mathrm{L}_{1}$ (Lot No. 111789-200901), Euphorbia factor $\mathrm{L}_{2}$ (Lot No. 111790200901), and Euphorbia factor $\mathrm{L}_{3}$ (Lot No. 111791-200901) have the purity of $99.3 \%, 98.5 \%$, and $98.6 \%$, respectively, which were obtained from China Institute of Pharmaceutical and Biological Products in Beijing, China, while wogonin (Lot No. YS0925SA13) with the purity of more than 98\% was obtained from Shanghai Yuanye Biotechnology Company LTD. in Shanghai, China.

2.2. Animals. Healthy Sprague-Dawley (SD) rats weighing $250 \pm 20 \mathrm{~g}$ and Kunming mice (KM) weighing $20 \pm 2 \mathrm{~g}$ were bought from SPF Biotechnology Company Ltd., in Beijing, China (Lot No. 2016-0002). The animals have free access to water and food. The animal experiment was carried out strictly according to the Provisions on the Administration of Experimental Animals issued by the Ministry of Science and
Technology of the People's Republic of China. The program was authorized by the Experimental Animal Ethics Committee of Beijing University of Chinese Medicine, and this study was carried out in strict compliance with the ARRIVE guidelines [19].

2.3. UPLC-MS/MS Conditions. The UPLC tandem quadrupole mass spectrometer (MS) (Acquity UPLC Xevo TQ-S, Waters, USA) and ACQUITY UPLC ${ }^{\circledR} \mathrm{BEH}$ C18 column $(1.7 \mu \mathrm{m}, 50 \mathrm{~mm} \times 2.1 \mathrm{~mm})$ were used. A gradient elution procedure of $0.1 \%$ formic acid (a)-methanol (b) was used for analysis. The elution procedure was as follows: $0-1$ minute ( $\min )(40 \% \mathrm{~b}) ; 1-2 \mathrm{~min}(40-75 \% \mathrm{~b}) ; 2-4 \mathrm{~min}(75-85 \% \mathrm{~b})$; 4-5 min $\quad(85-100 \% \quad b) ; \quad 5-7$ min $(100 \% \quad b) ; \quad 7-7.5 \mathrm{~min}$ $(100-40 \%$ b); $7.5-10 \mathrm{~min}(40 \%$ b). The flow rate was $0.4 \mathrm{~mL} \cdot \mathrm{min}^{-1}$, the column temperature was $40^{\circ} \mathrm{C}$, the detection wavelength was $275 \mathrm{~nm}$, and the injection volume was $2 \mu \mathrm{L}$. The sample extracts were maintained in the autosampler at $10^{\circ} \mathrm{C}$.

Electrospray ionization (ESI) source was used for MS detection under positive ion mode. The multi-ion monitoring (MRM) mode was used for scanning. The conditions of MS were as follows: desolvent gas flow rate, $800 \mathrm{~L} \cdot$ hour $^{-1}$ $\left(\mathrm{L} \cdot \mathrm{h}^{-1}\right)$; desolvent gas temperature, $400^{\circ} \mathrm{C}$; cone gas flow, $150 \mathrm{~L} \cdot \mathrm{h}^{-1}$; capillary voltage, $3.0 \mathrm{kV}$. Quantification was performed at $\mathrm{m} / \mathrm{z} 553 \longrightarrow 297$ (Euphorbia factor $\mathrm{L}_{1}$ ), $\mathrm{m} / \mathrm{z}$ $665 \longrightarrow 105$ (Euphorbia factor $\mathrm{L}_{2}$ ), m/z 545 $\longrightarrow 485(\mathrm{Eu}-$ phorbia factor $\mathrm{L}_{3}$ ), and $\mathrm{m} / \mathrm{z} 285 \longrightarrow 135$ (wogonin, internal standard, IS). The MS diagram of these components is shown in Figure 1.

\subsection{Preparation of Standard Solutions and Quality Control} Samples. The reference standards, including those of Euphorbia factors $\mathrm{L}_{1}, \mathrm{~L}_{2}$, and $\mathrm{L}_{3}$, were each weighed and diluted with methanol, yielding stock solutions with concentrations of $1.002,1.010$, and $1.002 \mathrm{mg} \cdot \mathrm{mL}^{-1}$. The stock solutions of Euphorbia factors $\mathrm{L}_{1}, \mathrm{~L}_{2}$, and $\mathrm{L}_{3}$ were then diluted with methanol to obtain the standard solutions with concentrations of $10.02,10.10$, and $10.02 \mu \mathrm{g} \cdot \mathrm{mL}^{-1}$, respectively.

The wogonin was precisely weighed and diluted to $25 \mathrm{~mL}$ using methanol, yielding a concentration of $2.016 \mu \mathrm{g} \cdot \mathrm{mL}^{-1}$ and then diluted with methanol to obtain the quality control (QC) solution with a concentration of $20.16 \mathrm{ng} \cdot \mathrm{mL}^{-1}$.

2.5. Sample Preparation. SE (500 g) and SEP (500 g) were extracted using the method described by Zhu et al. [20, 21]. SE and SEP were weighed and reflux extracted for three times using 95\% ethanol. The extracts from each reflux were filtered, the filtrates were combined and concentrated, followed by the addition of water to form a suspension. The suspension was extracted with an equal volume of petroleum ether for 3 times, and the supernatant was concentrated to obtain the SE extract with a concentration of $5.53 \mathrm{~g} \cdot \mathrm{mL}^{-1}$ for SE and the SEP extract with a concentration of $5.74 \mathrm{~g} \cdot \mathrm{mL}^{-1}$ for SEP. SE extract contains Euphorbia factor $L_{1}$ of $4.80 \mathrm{mg} \cdot \mathrm{g}^{-1}$, Euphorbia factor $\mathrm{L}_{2}$ of $2.21 \mathrm{mg} \cdot \mathrm{g}^{-1}$, and 


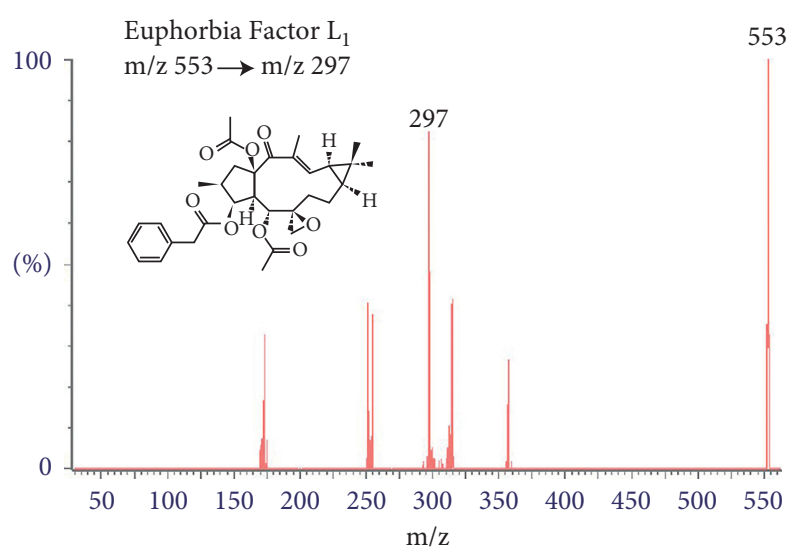

(a)

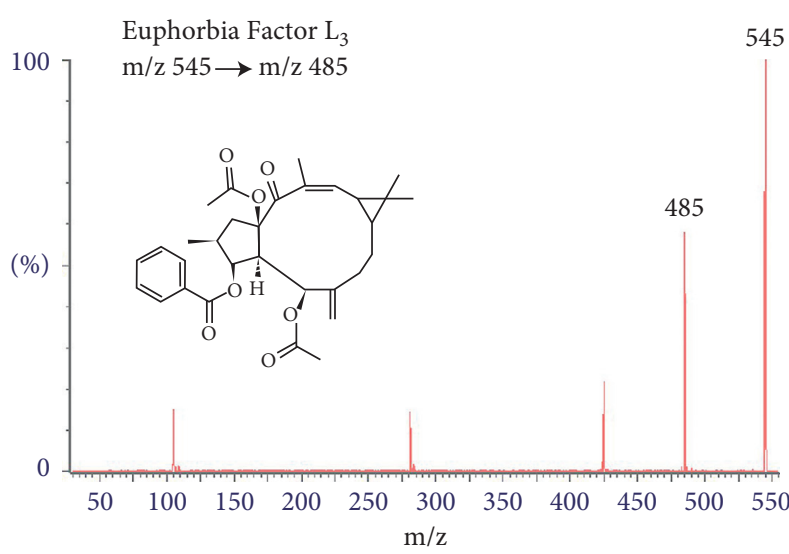

(c)

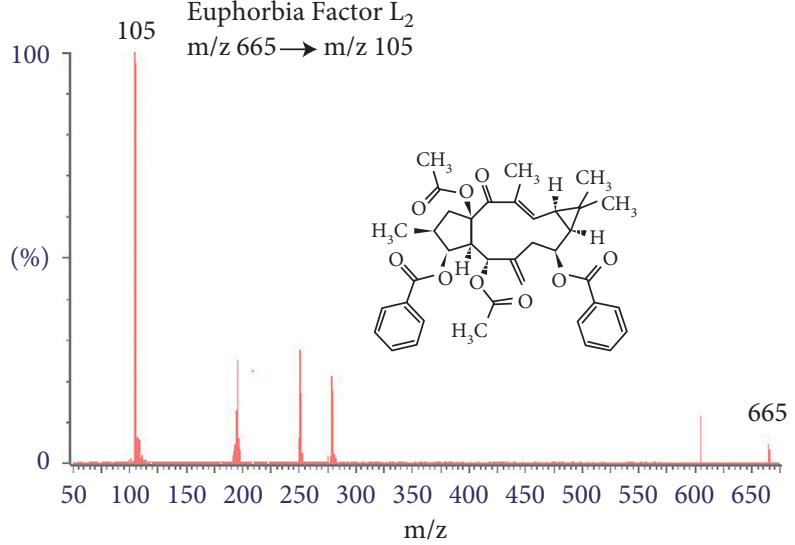

(b)

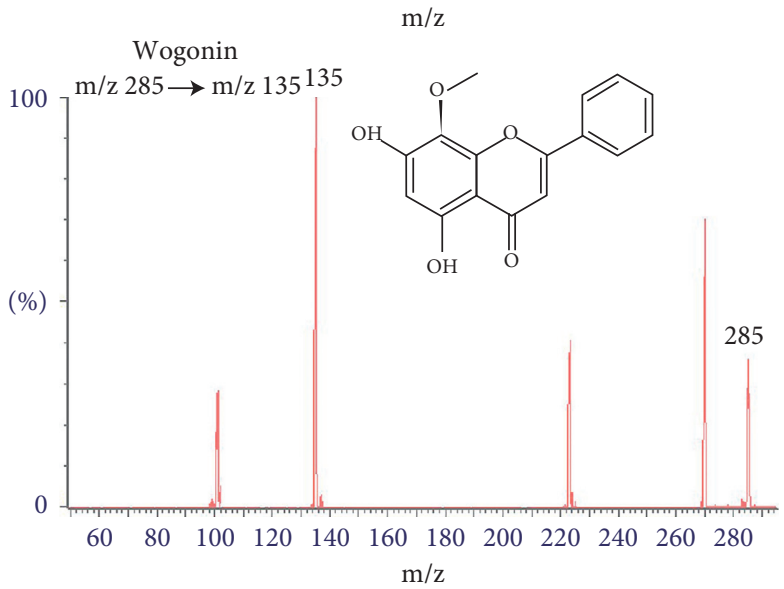

(d)

Figure 1: Full scan ion spectrum of Euphorbia factor $\mathrm{L}_{1}(\mathrm{a})$, Euphorbia factor $\mathrm{L}_{2}(\mathrm{~b})$, Euphorbia factor $\mathrm{L}_{3}(\mathrm{c})$, and IS (d) in positive ion mode.

Euphorbia factor $\mathrm{L}_{3}$ of $4.89 \mathrm{mg} \cdot \mathrm{g}^{-1}$, and SEP extract contains Euphorbia factor $\mathrm{L}_{1}$ of $2.75 \mathrm{mg} \cdot \mathrm{g}^{-1}$, Euphorbia factor $\mathrm{L}_{2}$ of $0.97 \mathrm{mg} \cdot \mathrm{g}^{-1}$, and Euphorbia factor $\mathrm{L}_{3}$ of $2.30 \mathrm{mg} \cdot \mathrm{g}^{-1}$, respectively.

2.6. Pretreatment of Plasma and Tissue Samples. Plasma $(100 \mu \mathrm{L})$ from each group was collected and $100 \mu \mathrm{L}$ wogonin solution with a concentration of $20.16 \mathrm{ng} \cdot \mathrm{mL}^{-1}$ and $1 \mathrm{~mL}$ ethyl acetate were added. The samples were then whirled for $5 \mathrm{~min}$, centrifuged at $8000 \mathrm{~g}$ for $10 \mathrm{~min}$. Next, $800 \mu \mathrm{L}$ of supernatant fluid was taken out and the remaining liquid was vortexed for $5 \mathrm{~min}$ and centrifuged at $8000 \mathrm{~g}$ for $10 \mathrm{~min}$. Then, all of the supernatant fluid were combined and dried under nitrogen at $37^{\circ} \mathrm{C}$. Subsequently, the dry extract was dissolved in $100 \mu \mathrm{L}$ of methanol, whirled for $1 \mathrm{~min}$, centrifuged at $8000 \mathrm{~g}$ for $5 \mathrm{~min}$, and the supernatant fluid was analyzed using UPLC-MS/MS. The tissue samples were prepared similarly.

2.7. Method Validation. The method was totally validated in accordance with the US FDA guidelines [22].
2.7.1. Selectivity. The selectivity was estimated by comparing chromatograms of blank plasma (tissue) samples without drugs, blank plasma without drugs added with IS solution, blank plasma (tissue) samples with IS solution and mixed standard solution, and plasma (tissue) samples from rat plasma or mouse tissues after the oral administration of SE and SEP, respectively.

2.7.2. Linear Range and Limit of Quantitation (LOQ). Standard curves were constructed with ten concentrations $\left(1,2,5,10,25,50,100,200,400\right.$, and $\left.800 \mathrm{ng} \cdot \mathrm{mL}^{-1}\right)$ of standard solution and blank plasma samples and then subjected to sample pretreatment. The linear range of each curve was estimated by means of the correlation coefficient $(r)$. The LOQ was defined as the minimum quantity of the measured substance in the sample, which reflected whether the method used was sensitive and well suited for quantitative detection.

2.7.3. Precision and Accuracy. The relative standard deviation (RSD) and relative error (RE) were used to estimate the precision and accuracy. Three QC samples (low, medium, 
and high) were used to test the intra- and interday accuracy and precision on the same day and three consecutive validation days.

2.7.4. Stability. Stability of the three components in rat plasma and mouse tissues was evaluated in low, middle, and high concentrations of QC samples using three replicates. The conditions are as follows: room temperature for $30 \mathrm{~min}$, three freeze-thaw cycles, and postpreparative samples stored in the automatic injector at $4^{\circ} \mathrm{C}$ for $24 \mathrm{~h}$.

2.7.5. Matrix Effect and Extraction Recovery. The extraction recoveries of the three components were defined by comparing the peak areas of the mixed standard solution and internal standard solution preadded to blank plasma with that postadded to blank plasma. The matrix effect was assessed by comparing the peak areas of the mixed standard solution and internal standard solution postadded to the blank plasma with those in the mobile phase.

2.8. Design of the Pharmacokinetic Study. A total of 12 male SD rats were divided into SE group and SEP group. The rats were fasted for $12 \mathrm{~h}$ before administration but could drink freely. SE and SEP extracts were dissolved in physiological saline to obtain a test solution containing $3.75 \mathrm{~g}$ of SE or SEP in $1 \mathrm{~mL}$ solution. Accordingly, six rats in each group were separately given SE and SEP test solution at a dose of $30 \mathrm{~g} \cdot \mathrm{kg}^{-1}$ by intragastric administration. $0.5 \mathrm{~mL}$ blood samples were taken from the fundus venous plexus at the specified time points (5 and $15 \mathrm{~min}, 0.5,1,1.5,2,4,8,12,24$, 36 , and $48 \mathrm{~h}$ ) before and after administration. At the end of the experiment, all rats were lightly anesthetized before euthanasia. The blood samples were immediately centrifuged at $8000 \mathrm{~g}$ for $10 \mathrm{~min}$. The plasma was stored at $-20^{\circ} \mathrm{C}$ until further analyses.

2.9. Design of the Tissue Distribution Study. SE and SEP extracts were dissolved in physiological saline to obtain a test solution containing $1.60 \mathrm{~g}$ of SE or SEP in $1 \mathrm{~mL}$ solution. A total of 72 male KM mice were orally administered SE and SEP test solution at a dose of $40 \mathrm{~g} \cdot \mathrm{kg}^{-1}$. Mice in the SE group were sacrificed by cervical dislocation after $4,8,12,16,24$, and $36 \mathrm{~h}$ following the administration of gavage, while mice in the SEP group were sacrificed after 2, 4, 8, 12, 24, and $36 \mathrm{~h}$. There are six mice in each group at each time point. The heart, liver, spleen, lung, kidney, and colon tissues were quickly dislodged, and the processed tissue samples were stored at $-20^{\circ} \mathrm{C}$ for further analysis.

2.10. Pharmacokinetic Parameters Analysis and Statistical Analysis. There were two groups of SE and SEP samples, with 6 samples in each group. The blood concentration of each sample was detected within the specified time, the pharmacokinetic parameters were analyzed using the DAS software package (version 2.0, Shanghai, China) by noncompartmental model, and the maximum concentration
$\left(C_{\max }\right)$, time to maximum concentration $\left(T_{\max }\right)$, half-life of elimination $\left(\mathrm{T}_{1 / 2 \mathrm{Z}}\right)$, area under the concentration time curve (AUC), apparent volume of distribution $\left(\mathrm{V}_{\mathrm{z} / \mathrm{F}}\right)$, clearance $\left(\mathrm{C}_{\mathrm{Lz} / \mathrm{E}}\right)$, and mean retention time (MRT) were calculated. A paired $t$-test analysis was conducted using the SPSS software (version 20.0, USA) to test whether these variables are different between the two groups. Data are expressed as mean \pm SD.

\section{Results}

\subsection{Method Validation}

3.1.1. Selectivity. The chromatograms of the three components and wogonin are shown in Figure 2. The chromatographic peaks of Euphorbia factors $\mathrm{L}_{1}, \mathrm{~L}_{2}$, and $\mathrm{L}_{3}$, and IS were well separated and were not affected by endogenous substances, indicating that the method has good selectivity.

\subsubsection{Linearity Range and Limit of Quantitation.} Standard curves of the three analytes are summarized in Tables 1 and 2. For each analytical run, the calibration curves of both plasma and tissue samples showed good linearity $(r>0.99)$ in the range of $1.002-808.0 \mathrm{ng} \cdot \mathrm{mL}^{-1}$. The LOQ of Euphorbia factors $\mathrm{L}_{1}, \mathrm{~L}_{2}$, and $\mathrm{L}_{3}$ were 1.002, 1.010 , and $1.002 \mathrm{ng} \cdot \mathrm{mL}^{-1}$, respectively. These results can provide sufficient sensitivity for subsequent pharmacokinetic studies.

3.1.3. Precision and Accuracy. According to Tables 3 and 4, the RSD of intra- and interday precision were all smaller than $15.0 \%$, while the corresponding accuracy was within $5 \%$. These data have shown that the precision and accuracy of this method are acceptable.

3.1.4. Stability. The stability of the three components in rat plasma and mouse tissues under various conditions is shown in Tables 5 and 6 . The RSD values of the three components ranged from 0.15 to $7.81 \%$, indicating that the components in rat plasma and mouse tissues were stable after storage at room temperature for $30 \mathrm{~min}$, at $4^{\circ} \mathrm{C}$ for $24 \mathrm{~h}$, and three freeze-thaw cycles.

3.1.5. Matrix Effect and Extraction Recovery. The matrix effects and extraction recoveries of the three components in rat plasma and mouse tissues are shown in Tables 7 and 8. All analytes had satisfactory extraction recovery from 95.10-114.14\%. Meanwhile, the matrix effect values of the three active ingredients ranged from $84.72-110.35 \%$. These results showed that the values of matrix effect and extraction recovery were within the acceptable range.

3.1.6. Pharmacokinetic Study. The established UPLC-MS/ MS method was applied to the pharmacokinetic study of Euphorbia factors $\mathrm{L}_{1}, \mathrm{~L}_{2}$, and $\mathrm{L}_{3}$ in rat plasma after oral administration of SE and SEP extracts, respectively. The concentration time curves after oral administration of the SE 


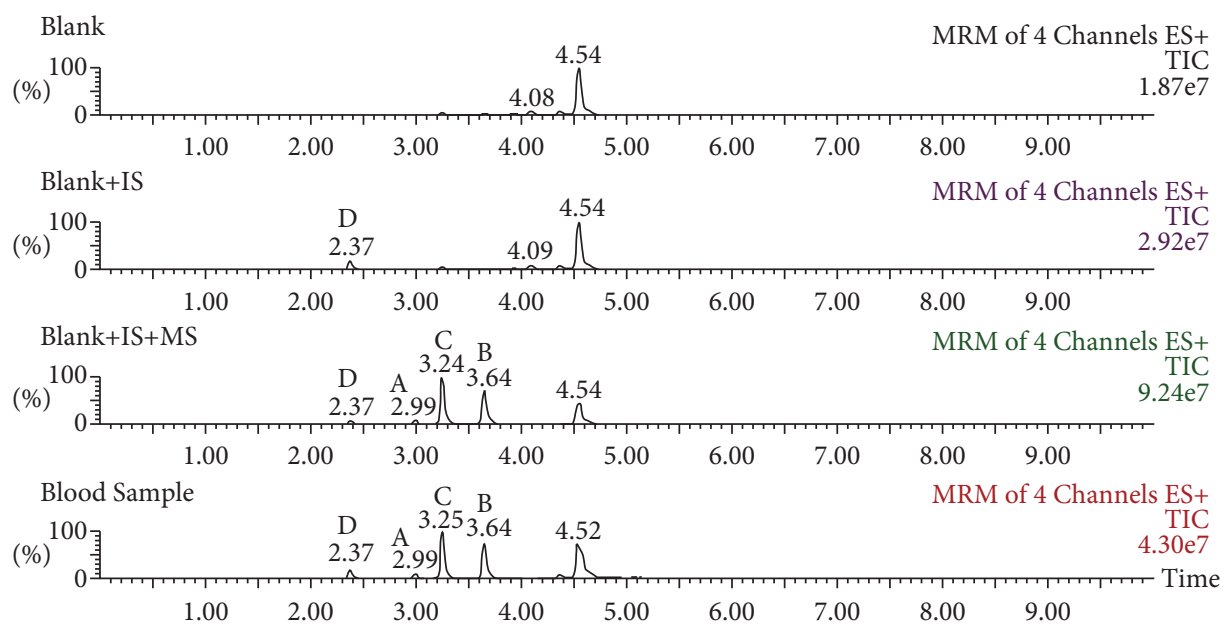

FIgURE 2: The chromatograms of three components and wogonin. (A, Euphorbia factor $\mathrm{L}_{1}$; $\mathrm{B}$, Euphorbia factor $\mathrm{L}_{2}$; , Euphorbia factor $\mathrm{L}_{3}$; D, wogonin).

TABLE 1: Linear relationship of the three analytes in rat plasma samples.

\begin{tabular}{lcccc}
\hline Analytes & Standard curve & $r$ & Linear range $\left(\mathrm{ng} \cdot \mathrm{mL}^{-1}\right)$ & $\mathrm{LOQ}\left(\mathrm{ng} \cdot \mathrm{mL} L^{-1}\right)$ \\
\hline Euphorbia factor $\mathrm{L}_{1}$ & $Y=0.0205841 X+0.0190221$ & 0.9990 & $1.002-801.6$ & 1.002 \\
Euphorbia factor $\mathrm{L}_{2}$ & $Y=0.234217 X+0.133849$ & 0.9955 & $1.010-808.0$ & 1.010 \\
Euphorbia factor $\mathrm{L}_{3}$ & $Y=0.192309 X+0.188019$ & 0.9977 & $1.002-801.6$ & 1.002 \\
\hline
\end{tabular}

TABLE 2: Linear relationship of three analytes in tissue samples of mice.

\begin{tabular}{|c|c|c|c|c|c|}
\hline Analytes & Tissue & Standard curve & $r$ & Linear range $\left(\mathrm{ng} \cdot \mathrm{mL}^{-1}\right)$ & LOQ $\left(\mathrm{ng} \cdot \mathrm{mL}^{-1}\right)$ \\
\hline \multirow{6}{*}{ Euphorbia factor $\mathrm{L}_{1}$} & Heart & $Y=0.034618 X+0.00207128$ & 0.9932 & \multirow{6}{*}{$1.002-801.6$} & \multirow{6}{*}{1.002} \\
\hline & Liver & $Y=0.00977173 X+0.00916433$ & 0.9990 & & \\
\hline & Spleen & $Y=0.117309 X+0.00187417$ & 0.9980 & & \\
\hline & Lung & $Y=0.0817354 X+0.0872459$ & 0.9976 & & \\
\hline & Kidney & $Y=0.00450416 X+0.000260721$ & 0.9987 & & \\
\hline & Colon & $Y=0.0349301 X+0.022299$ & 0.9976 & & \\
\hline \multirow{6}{*}{ Euphorbia factor $\mathrm{L}_{2}$} & Heart & $Y=0.400486 X+0.23513$ & 0.9978 & \multirow{6}{*}{$1.010-808.0$} & \multirow{6}{*}{1.010} \\
\hline & Liver & $Y=0.188429 X+0.0965572$ & 0.9935 & & \\
\hline & Spleen & $Y=1.0453 \mathrm{X}-0.17471$ & 0.9955 & & \\
\hline & Lung & $Y=0.502219 X+0.344347$ & 0.9980 & & \\
\hline & Kidney & $Y=0.294794 X+0.2747$ & 0.9922 & & \\
\hline & Colon & $Y=0.313598 X+0.332799$ & 0.9924 & & \\
\hline \multirow{6}{*}{ Euphorbia factor $\mathrm{L}_{3}$} & Heart & $Y=0.250723 X+0.120749$ & 0.9959 & \multirow{6}{*}{$1.002-801.6$} & \multirow{6}{*}{1.002} \\
\hline & Liver & $Y=0.192895 X+0.0424932$ & 0.9983 & & \\
\hline & Spleen & $Y=0.581293 X-0.0697721$ & 0.9985 & & \\
\hline & Lung & $Y=0.346932 X+0.11191$ & 0.9953 & & \\
\hline & Kidney & $Y=0.207445 X+0.0897848$ & 0.9970 & & \\
\hline & Colon & $Y=0.281536 X+0.176594$ & 0.9979 & & \\
\hline
\end{tabular}

or SEP extracts are shown in Figure 3. The main pharmacokinetic parameters are shown in Table 9.

It can be seen from the chart that the pharmacokinetics of Euphorbia factors $\mathrm{L}_{1}, \mathrm{~L}_{2}$, and $\mathrm{L}_{3}$ are similar, showing a slow absorption rate after administration. In the crude SE, the $T_{\max }$ values of three components were more than $10 \mathrm{~h}$. After the administration of SEP extract to rats by gavage, the time to maximum concentration $\left(T_{\max }\right)$ of Euphorbia factor $\mathrm{L}_{1}$ was significantly less than that for crude SE $(p<0.01)$, and the time to maximum concentration $\left(T_{\max }\right)$ of Euphorbia factors $L_{2}$ and $L_{3}$ was also less than that for crude $S E$ $(p<0.05)$, with each $T_{\max }<10 \mathrm{~h}$, indicating that these diterpene esters can reach the maximum blood concentration within $10 \mathrm{~h}$ after processing, and they were absorbed more rapidly in vivo after processing. After giving the same dose of SE and SEP, the area under the concentration time curve (AUC) of Euphorbia factors $\mathrm{L}_{2}$ and $\mathrm{L}_{3}$ in SEP group was significantly lower than those of SE group $(p<0.05)$, among which the AUC of Euphorbia factor $\mathrm{L}_{3}$ was found to be the highest among the three analytes. The mean retention time (MRT) of Euphorbia factor $\mathrm{L}_{2}$ in SEP was lower than that of SE $(p<0.05)$, indicating that the action time 
TABLE 3: Precision and accuracy of the three analytes in rat plasma samples.

\begin{tabular}{|c|c|c|c|c|}
\hline \multirow{2}{*}{ Analytes } & \multirow{2}{*}{ Concentration $\left(\mathrm{ng} \cdot \mathrm{mL}^{-1}\right)$} & \multicolumn{2}{|c|}{ RSD (\%) } & \multirow{2}{*}{$\begin{array}{c}\text { RE (\%) } \\
\text { Accuracy }\end{array}$} \\
\hline & & Intra-assay precision & Interassay precision & \\
\hline \multirow{3}{*}{ Euphorbia factor $\mathrm{L}_{1}$} & 25 & 1.68 & 2.98 & 0.09 \\
\hline & 100 & 5.12 & 2.68 & 0.13 \\
\hline & 400 & 1.85 & 2.40 & 0.13 \\
\hline \multirow{3}{*}{ Euphorbia factor $\mathrm{L}_{2}$} & 25 & 1.35 & 2.99 & -0.24 \\
\hline & 100 & 1.40 & 11.07 & -0.84 \\
\hline & 400 & 2.10 & 6.01 & 0.23 \\
\hline \multirow{3}{*}{ Euphorbia factor $\mathrm{L}_{3}$} & 25 & 1.39 & 2.83 & 0.12 \\
\hline & 100 & 2.00 & 2.31 & -0.50 \\
\hline & 400 & 1.35 & 6.39 & -1.49 \\
\hline
\end{tabular}

TABLe 4: Precision and accuracy of the three analytes in tissue samples of mice.

\begin{tabular}{|c|c|c|c|c|}
\hline \multirow{2}{*}{ Samples } & \multirow{2}{*}{ Concentration $\left(\mathrm{ng} \cdot \mathrm{mL}^{-1}\right)$} & \multicolumn{2}{|c|}{ RSD (\%) } & \multirow{2}{*}{$\begin{array}{c}\text { RE (\%) } \\
\text { Accuracy }\end{array}$} \\
\hline & & Intra-assay precision & Interassay precision & \\
\hline \multirow{3}{*}{ Euphorbia factor $\mathrm{L}_{1}$} & 10 & 2.40 & 2.37 & 0.48 \\
\hline & 200 & 0.81 & 1.33 & -0.39 \\
\hline & 600 & 0.89 & 0.91 & -0.21 \\
\hline \multirow{3}{*}{ Euphorbia factor $\mathrm{L}_{2}$} & 10 & 2.63 & 5.19 & 0.09 \\
\hline & 200 & 0.84 & 1.96 & 0.03 \\
\hline & 600 & 1.18 & 1.60 & 0.09 \\
\hline \multirow{3}{*}{ Euphorbia factor $\mathrm{L}_{3}$} & 10 & 1.98 & 1.95 & -0.07 \\
\hline & 200 & 0.87 & 1.05 & -0.58 \\
\hline & 600 & 1.16 & 1.27 & -0.85 \\
\hline
\end{tabular}

TABLE 5: Stability of the three analytes in rat plasma samples.

\begin{tabular}{lcccc}
\hline Analytes & $\begin{array}{c}\text { Concentration } \\
\left(\text { ng } \cdot \mathrm{mL}^{-1}\right)\end{array}$ & $\begin{array}{c}\text { At room temperature for } 30 \text { min in } \\
\text { plasma }\end{array}$ & $\begin{array}{c}\text { RSD (\%) } \\
\text { At } 4^{\circ} \mathrm{C} \text { for 24h in } \\
\text { plasma }\end{array}$ & $\begin{array}{c}\text { After three freeze-thaw cycles in } \\
\text { plasma }\end{array}$ \\
\hline Euphorbia factor & 25 & 7.14 & 2.96 & 1.01 \\
$\mathrm{~L}_{1}$ & 100 & 1.16 & 2.18 & 2.69 \\
\hline \multirow{2}{*}{ Euphorbia factor } & 400 & 1.74 & 1.35 & 3.08 \\
$\mathrm{~L}_{2}$ & 100 & 1.79 & 5.99 & 4.68 \\
\hline \multirow{2}{*}{ Euphorbia factor } & 400 & 3.57 & 0.97 & 1.93 \\
$\mathrm{~L}_{3}$ & 25 & 2.08 & 3.60 & 3.83 \\
\hline
\end{tabular}

TABLE 6: Stability of the three analytes in tissue samples of mice.

\begin{tabular}{|c|c|c|c|c|}
\hline \multirow[b]{2}{*}{ Analytes } & \multirow[b]{2}{*}{$\begin{array}{l}\text { Concentration } \\
\left(\mathrm{ng} \cdot \mathrm{mL}^{-1}\right)\end{array}$} & \multicolumn{3}{|c|}{ RSD (\%) } \\
\hline & & $\begin{array}{l}\text { At room temperature for } 30 \mathrm{~min} \text { in } \\
\text { tissue }\end{array}$ & $\begin{array}{c}\text { At } 4^{\circ} \mathrm{C} \text { for } 24 \mathrm{~h} \text { in } \\
\text { tissue }\end{array}$ & $\begin{array}{l}\text { After three freeze-thaw cycles in } \\
\text { tissue }\end{array}$ \\
\hline \multirow{3}{*}{$\begin{array}{l}\text { Euphorbia factor } \\
\mathrm{L}_{1}\end{array}$} & 10 & 3.43 & 0.81 & 3.25 \\
\hline & 200 & 1.97 & 3.06 & 1.59 \\
\hline & 600 & 0.15 & 4.33 & 1.80 \\
\hline \multirow{3}{*}{$\begin{array}{l}\text { Euphorbia factor } \\
\mathrm{L}_{2}\end{array}$} & 10 & 2.38 & 1.13 & 7.81 \\
\hline & 200 & 2.05 & 0.99 & 1.19 \\
\hline & 600 & 0.71 & 1.40 & 2.35 \\
\hline \multirow{3}{*}{$\begin{array}{l}\text { Euphorbia factor } \\
\mathrm{L}_{3}\end{array}$} & 10 & 1.86 & 3.56 & 1.41 \\
\hline & 200 & 3.41 & 1.99 & 4.68 \\
\hline & 600 & 0.18 & 1.94 & 4.06 \\
\hline
\end{tabular}


TABLE 7: Recovery and matrix effect of the three analytes in rat plasma samples.

\begin{tabular}{|c|c|c|c|c|c|}
\hline \multirow{2}{*}{ Analytes } & \multirow{2}{*}{ Concentration $\left(\mathrm{ng} \cdot \mathrm{mL}^{-1}\right)$} & \multicolumn{2}{|c|}{ Mean (\%) } & \multicolumn{2}{|c|}{ RSD (\%) } \\
\hline & & Matrix effect & Extraction recovery & Matrix effect & Extraction recovery \\
\hline \multirow{3}{*}{ Euphorbia factor $\mathrm{L}_{1}$} & 25 & 104.42 & 101.17 & 3.61 & 3.81 \\
\hline & 100 & 89.15 & 99.84 & 1.26 & 4.09 \\
\hline & 400 & 95.97 & 100.79 & 1.94 & 2.83 \\
\hline \multirow{3}{*}{ Euphorbia factor $\mathrm{L}_{2}$} & 25 & 110.35 & 105.83 & 1.88 & 5.45 \\
\hline & 100 & 99.24 & 101.85 & 1.80 & 5.10 \\
\hline & 400 & 109.95 & 98.89 & 0.85 & 1.46 \\
\hline \multirow{3}{*}{ Euphorbia factor $\mathrm{L}_{3}$} & 25 & 92.64 & 114.14 & 1.83 & 1.33 \\
\hline & 100 & 84.72 & 111.71 & 1.45 & 4.00 \\
\hline & 400 & 94.07 & 112.72 & 1.24 & 0.80 \\
\hline
\end{tabular}

TABLE 8: Recovery and matrix effect of the three analytes in tissue samples of mice.

\begin{tabular}{|c|c|c|c|c|c|}
\hline \multirow{2}{*}{ Analytes } & \multirow{2}{*}{ Concentration $\left(\mathrm{ng} \cdot \mathrm{mL}^{-1}\right)$} & \multicolumn{2}{|c|}{ Mean (\%) } & \multicolumn{2}{|c|}{ RSD (\%) } \\
\hline & & Matrix effect & Extraction recovery & Matrix effect & Extraction recovery \\
\hline \multirow{3}{*}{ Euphorbia factor $\mathrm{L}_{1}$} & 10 & 101.57 & 98.50 & 0.95 & 1.96 \\
\hline & 200 & 104.00 & 100.67 & 0.46 & 1.14 \\
\hline & 600 & 99.63 & 102.7 & 0.76 & 1.63 \\
\hline \multirow{3}{*}{ Euphorbia factor $\mathrm{L}_{2}$} & 10 & 98.97 & 104.07 & 1.69 & 0.76 \\
\hline & 200 & 101.10 & 97.10 & 1.89 & 2.27 \\
\hline & 600 & 105.40 & 95.10 & 0.59 & 2.01 \\
\hline \multirow{3}{*}{ Euphorbia factor $\mathrm{L}_{3}$} & 10 & 99.33 & 101.00 & 3.29 & 2.77 \\
\hline & 200 & 102.40 & 98.23 & 2.71 & 2.14 \\
\hline & 600 & 103.63 & 102.47 & 2.09 & 1.63 \\
\hline
\end{tabular}

shortened in vivo after processing. Compared with SE group, the maximum concentration $\left(C_{\max }\right)$ of the three components in the blood of SEP group decreased. In terms of the half-life of elimination $\left(\mathrm{T}_{1 / 2 \mathrm{Z}}\right)$, the $\mathrm{T}_{1 / 2 \mathrm{Z}}$ values of the three compounds were $9.53,9.57$, and 9.35 h for SE, but $8.42,7.42$, and $7.46 \mathrm{~h}$ for SEP, which suggested that SEP was quickly eliminated while SE was more slowly eliminated.

3.1.7. Tissue Distribution Study. The tissue distribution of Euphorbia factors $\mathrm{L}_{1}, \mathrm{~L}_{2}$, and $\mathrm{L}_{3}$ after oral administration of the SE or SEP extract was investigated by collecting tissues including the heart, liver, spleen, lung, kidney, and colon tissues. The mean concentration versus time profiles of Euphorbia factors $\mathrm{L}_{1}, \mathrm{~L}_{2}$, and $\mathrm{L}_{3}$ in the mouse tissues are shown in Figure 4. Based on the experimental results, after mice were administered SE and SEP extracts by gavage, Euphorbia factors $\mathrm{L}_{1}, \mathrm{~L}_{2}$, and $\mathrm{L}_{3}$ could be detected in the heart, liver, spleen, lung, kidney, and colon tissues. Among which, the highest tissue concentration of Euphorbia factors $\mathrm{L}_{1}, \mathrm{~L}_{2}$, and $\mathrm{L}_{3}$ in $\mathrm{SE}$ group was detected in the colon $\left(235.43 \mathrm{ng} \cdot \mathrm{g}^{-1}, 284.47 \mathrm{ng} \cdot \mathrm{g}^{-1}, 567.52 \mathrm{ng} \cdot \mathrm{g}^{-1}\right)$, followed by the liver $\left(53.39 \mathrm{ng} \cdot \mathrm{g}^{-1}, 247.95 \mathrm{ng} \cdot \mathrm{g}^{-1}, 259.69 \mathrm{ng} \cdot \mathrm{g}^{-1}\right.$ ) and the kidney $\left(36.23 \mathrm{ng} \cdot \mathrm{g}^{-1}, 145.52 \mathrm{ng} \cdot \mathrm{g}^{-1}, 159.92 \mathrm{ng} \cdot \mathrm{kg}^{-1}\right.$ ), while the highest tissue concentration of Euphorbia factors $L_{1}, L_{2}$, and $\mathrm{L}_{3}$ in SEP group was detected in the colon $\left(117.97 \mathrm{ng} \cdot \mathrm{g}^{-1}, 91.44 \mathrm{ng} \cdot \mathrm{g}^{-1}, 310.04 \mathrm{ng} \cdot \mathrm{g}^{-1}\right)$, followed by the liver $\left(27.55 \mathrm{ng}^{-1} \mathrm{~g}^{-1}, 58.37 \mathrm{ng} \cdot \mathrm{g}^{-1}, 143.81 \mathrm{ng} \cdot \mathrm{g}^{-1}\right)$ and the kidney (21.55 $\left.\mathrm{ng} \cdot \mathrm{g}^{-1}, 61.59 \mathrm{ng} \cdot \mathrm{g}^{-1}, 89.92 \mathrm{ng} \cdot \mathrm{kg}^{-1}\right)$. Besides, almost all tissues reached the highest concentration level at the $4 \mathrm{~h}$ after administration and then began to decline; the levels of the three analytes in tissues were almost undetectable after $36 \mathrm{~h}$.

\section{Discussion}

4.1. Sample Pretreatment Optimization. In the preliminary protein precipitation experiment, the liquid-liquid extraction of ethyl acetate, ether, and n-butanol was studied for sample preparation. With the extraction yield of three characteristic components and the disturbance degree of endogenous substances were used as indices, the results revealed that ethyl acetate had better extraction rate for all analytes in selectivity and sensitivity. Therefore, ethyl acetate extraction method was selected to treat the biological samples.

4.2. UPLC-MS/MS Optimization. In our previous study, we determined the retention time, $\mathrm{m} / \mathrm{z}$, and ionic strength of chemical composition in SE and SEP using UPLC-MS/MS. The differences in chemical composition were significant between SE and SEP. Using the negative ion mode, the active components detected in SE and SEP were palmitic acid, oleic acid, aesculetin, and euphorbetin, while most lathyrane diterpenoid-type compounds were detected using the positive ion mode [23]. Thus, the positive ion mode was used to analyze the differences between SE and SEP.

4.3. Selection of IS. The retention time and extraction recovery of wogonin were similar to that of Euphorbia factors $\mathrm{L}_{1}, \mathrm{~L}_{2}$, and $\mathrm{L}_{3}$, while the ion response was similar to that of the component 

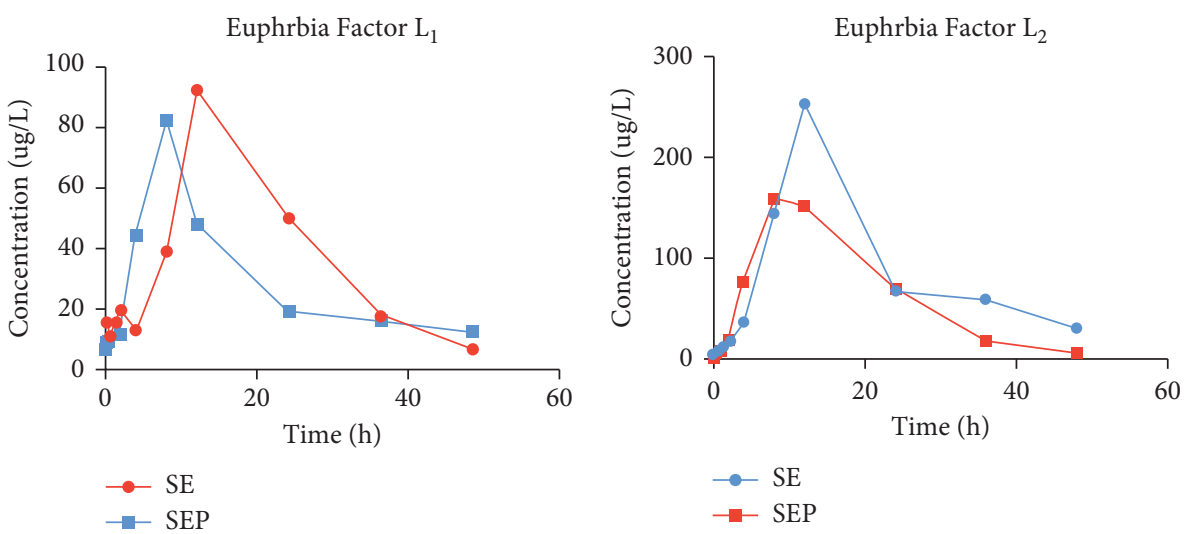

(a)

(b)

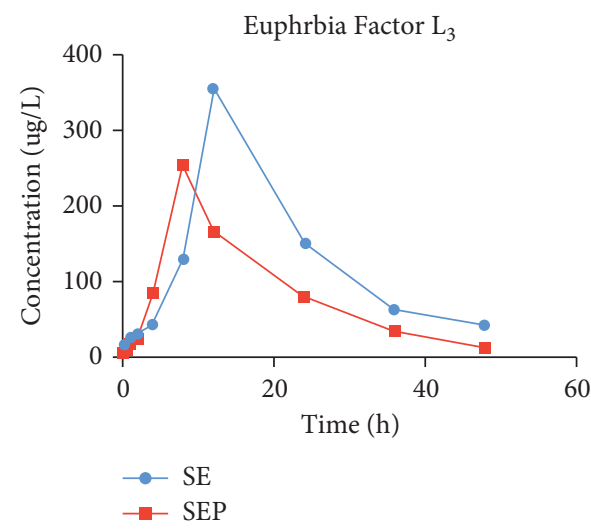

(c)

Figure 3: The concentration time curve of Euphorbia factor $\mathrm{L}_{1}(\mathrm{a})$, Euphorbia factor $\mathrm{L}_{2}(\mathrm{~b})$, and Euphorbia factor $\mathrm{L}_{3}(\mathrm{c})$ in rat plasma after oral administration of SE or SEP extract $(n=6)$.

to be measured. Wogonin can be completely separated from the three analytes, and the SE and SEP do not contain wogonin. Therefore, wogonin was chosen as an internal standard.

4.4. Pharmacokinetic Study. The three active compounds shared some similar pharmacokinetic parameters, which may be due to the similarity of their structures. There are two acetate groups and one phenylacetate group in the structure of diterpene ester, which can be hydrolyzed under the action of plasma esterase. It has been reported that the three ester groups of diterpenes are all hydrolyzed to epoxy lathyrol under the action of esterase [16], and the polarity of the solvent, the strength of the alkali, the concentration of the alkali, the temperature, the time, and other factors all affect the metabolism of the diterpene esters [16, 24]. Therefore, the plasma concentrations of the three diterpene esters decreased rapidly from peak concentrations in a short period of time, which may be caused by the metabolism of the diterpene esters in plasma esterase. In addition, these three components have long $\mathrm{T}_{1 / 2 \mathrm{z}}$, which may be due to the high binding rate between the drug and serum protein; the lower the concentration of the free drug, the lower the clearance rate of the drug and the longer the halflife time. Besides, all the three analytes have a relatively low $C_{\text {max }}$, the main reason may be that more than half of the three analytes have been excreted [17], and after 48 hours of intragastric administration of SE and SEP extracts, the three components were almost undetectable in plasma, which is consistent with the research of Fu [16]. However, the results of this experiment are also different from those of $\mathrm{Fu}$ and Meng $[16,17]$; it is speculated that the different drugs by gavage may be the reason for the difference in experimental results. In this study, petroleum ether extract of SE was given intragastric administration while in the literature study, diterpene ester monomer and ethanol extract of SE were given intragastric administration. The complex components contained in the extract may interact with each other and result in inconsistency with the monomer components in vivo, which may be the reason why the literature is inconsistent with our experimental results.

4.5. Tissue Distribution Study. The results indicated that Euphorbia factors $\mathrm{L}_{1}, \mathrm{~L}_{2}$, and $\mathrm{L}_{3}$ had good fat solubility and tissue affinity and underwent a rapid and wide distribution into tissues. However, the time to highest concentrations in various tissues was relatively slow, and the active component concentrations in colon, liver, and kidney tissues were more, followed by that in the heart, lung, and spleen. The total amount of three active compounds in the colon was significantly higher than that in other tissues, demonstrating that SE and SEP were mainly accumulated in the colon and suggesting 


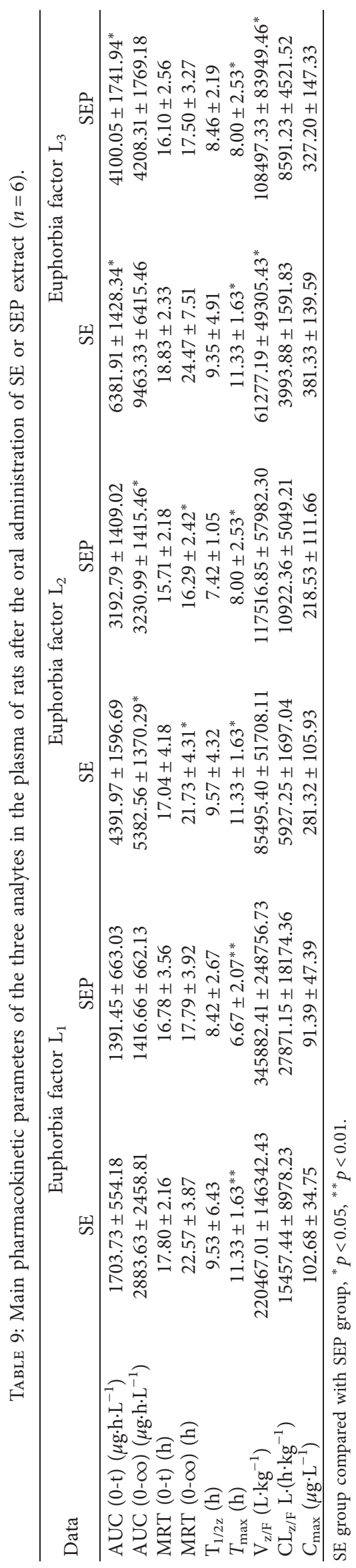




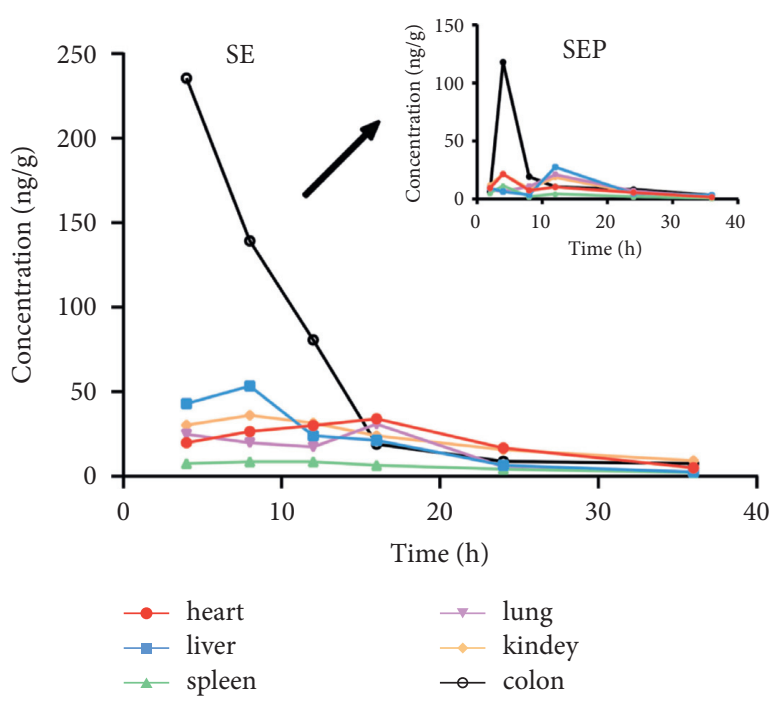

(a)

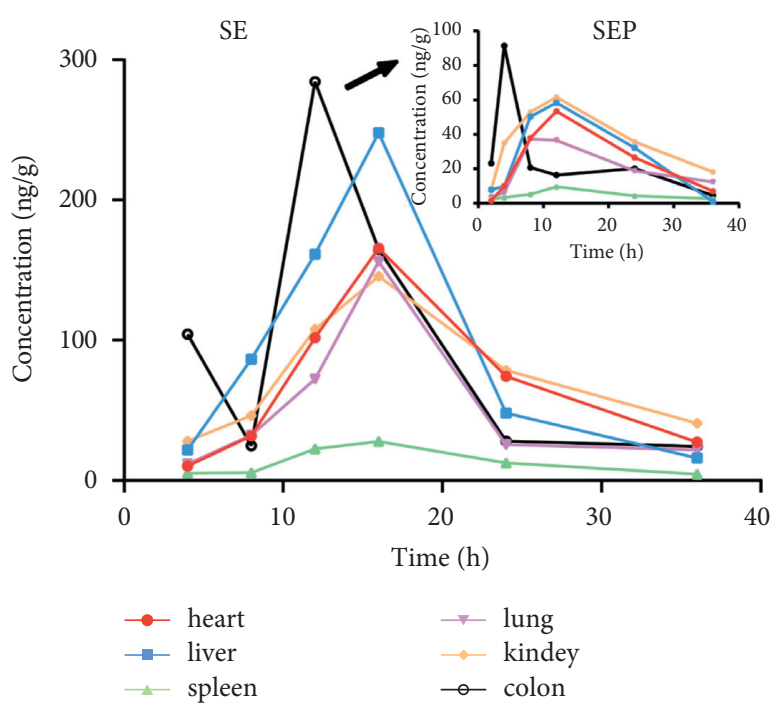

(b)

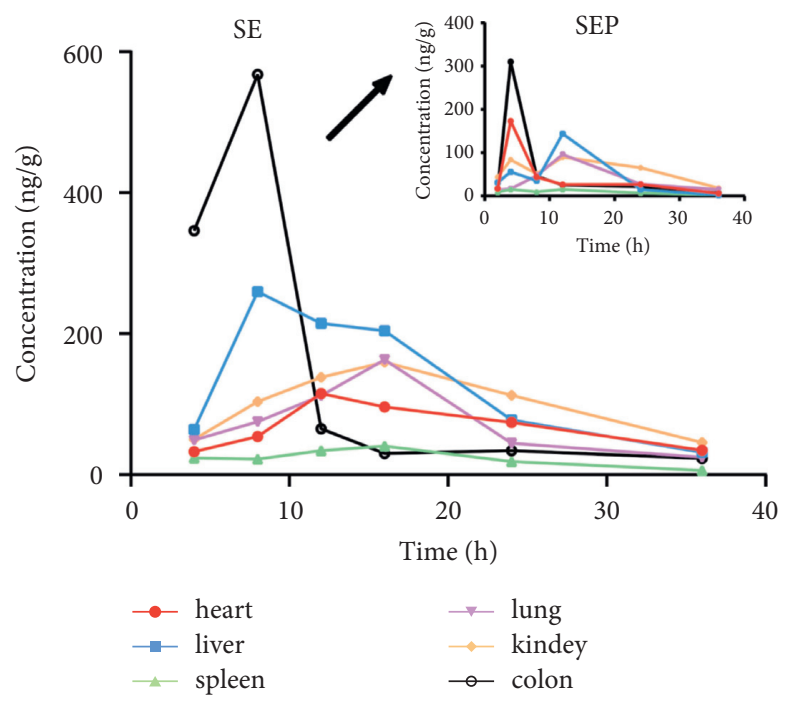

(c)

Figure 4: Concentration distribution of Euphorbia factor $\mathrm{L}_{1}$ (a), Euphorbia factor $\mathrm{L}_{2}$ (b), and Euphorbia factor $\mathrm{L}_{3}(\mathrm{c})$ at different time points in tissue samples of mice after oral administration of SE or SEP extract $(n=6)$.

a potential role of this organ in the metabolism of SE. The concentrations of each compound in different tissues varied greatly, and the concentrations and peak time of the three diterpene esters in the same tissue also differed, which may be related to the difference in blood flow between tissues after drug absorption, the difference in drug composition, the binding force between tissues, and the oral route of drug administration. In addition, the levels of the three analytes in each tissue decreased after processing and the differences were found to be statistically significant at individual time points.

\section{Conclusion}

In our study, a quantitative method for the determination of Euphorbia factors $\mathrm{L}_{1}, \mathrm{~L}_{2}$, and $\mathrm{L}_{3}$ was established by UPLC-MS/ MS. This method was found to be rapid, selective, sensitive, and reliable, with good precision and accuracy, and was applied to determine the pharmacokinetics and assess the distribution characteristics of SE and SEP. Our results revealed the processing could influence the pharmacokinetics and tissue distribution of Euphorbia factors $\mathrm{L}_{1}, \mathrm{~L}_{2}$, and $\mathrm{L}_{3}$ after oral administration of crude and processed SE. The results from our study could lay a foundation for the clinical use of SE and for further study on the processing mechanism of SE.

\section{Data Availability}

The data used to support the findings of this study are included within the article.

\section{Conflicts of Interest}

The authors declare that there are no conflicts of interest regarding the publication of this paper. 


\section{Authors' Contributions}

Hui-Nan Wang carried out the lab work, participated in the design of the study, and drafted the manuscript. Pei-Hua Wang, Zi-Ye Yang, Gui-Mei Zhang, Meng-Yu Chen, and Ming-Rui Jiang performed the experiments and carried out the statistical analyses. Zhu-Zhu Yue, Zhi-Cheng Wang, Jing-Qiu Zhang, Yan-Hua Cao, and Hong An collected the field data and critically revised the manuscript. Ying-Zi Wang conceived the study, designed the study, coordinated the study, and helped draft the manuscript. All authors read and approved the final manuscript.

\section{Acknowledgments}

This research was supported by the National Natural Science Foundation of China (Grant no. 82074021) and the National Key Research and Development Program of China (Grant no. 2018YFE0197900).

\section{References}

[1] Q.-W. Shi, X.-H. Su, and H. Kiyota, "Chemical and pharmacological research of the plants in genus Euphorbia," Chemical Reviews, vol. 108, no. 10, pp. 4295-4327, 2008.

[2] Y.-S. Wang, G.-W. Song, H.-W. Zhang, R.-H. Wu, and Z.-L. Zhang, "Analysis of semen euphorbiae frostlike powders by HPLC fingerprint," Asian Journal of Chemistry, vol. 25, no. 17, pp. 10011-10014, 2013.

[3] H.-W. Cheng, J.-G. He, and W.-Y. He, "Anticancer properties of semen Euphorbiae towards ACHN human renal adenocarcinoma cells by inducing apoptosis," Saudi Journal of Biological Sciences, vol. 25, no. 6, pp. 1146-1153, 2018.

[4] Y.-N. Teng, Y.-Z. Wang, P.-L. Hsu et al., "Mechanism of action of cytotoxic compounds from the seeds of Euphorbia lathyris," Phytomedicine, vol. 41, pp. 62-66, 2018.

[5] A. Zhu, T. Zhang, and Q. Wang, "The phytochemistry, pharmacokinetics, pharmacology and toxicity of Euphorbia semen," Journal of Ethnopharmacology, vol. 227, pp. 41-55, 2018.

[6] Y. Zhang, Y.-Z. Wang, S.-J. Li et al., "ITRAQ-based quantitative proteomic analysis of processed Euphorbia lathyris L. for reducing the intestinal toxicity," Proteome Science, vol. 16, no. 1, p. 8, 2018.

[7] S.-K. Wong, C.-M. Lau, X.-L. Su, R.-C. Lin, S.-W. Cheng, and K.-P. Fung, "Characterization of semen euphorbiae," Proceedings of The Society for Experimental Biology and Medicine, vol. 128, no. 1, pp. 75-80, 2011.

[8] Z. Chen, L. Hu, Y. Liao et al., "Different processed products of Curcumae Radix regulate pain-related substances in a rat model of Qi Stagnation and blood stasis," Frontiers in Pharmacology, vol. 11, pp. 242-250, 2020.

[9] Y. Ning, K. Pei, G. Cao et al., "Comparative study on pharmacokinetics of four active compounds in rat plasma after oral administration of raw and wine processed Chuanxiong Rhizoma," Molecules, vol. 25, no. 1, pp. 93-118, 2019.

[10] Y.-H. Wang, G.-W. Song, H.-W. Zhang, R.-H. Wu, and Z.-L. Zhang, "Simultaneous assay of three diterpenoids with one marker in semen euphorbiae pulveratum," Asian Journal of Chemistry, vol. 26, no. 4, pp. 1179-1185, 2014.

[11] C.-Y. Zhang, Y.-L. Wu, P. Zhang, Z.-Z. Chen, H. Li, and L.-X. Chen, "Anti-inflammatory lathyrane diterpenoids from
Euphorbia lathyris," Journal of Natural Products, vol. 82, no. 4, pp. 756-764, 2019.

[12] S.-E. Hong, J. Lee, D.-H. Seo et al., "Euphorbia factor $\mathrm{L}_{1}$ inhibits osteoclastogenesis by regulating cellular redox status and induces Fas-mediated apoptosis in osteoclast," Free Radical Biology and Medicine, vol. 112, pp. 191-199, 2017.

[13] J.-X. Wang, Q. Wang, Y.-Q. Zhen, S.-M. Zhao, F. Gao, and X.-L. Zhou, "Cytotoxic lathyrane-type diterpenes from seeds of Euphorbia lathyris," Chemical and Pharmaceutical Bulletin, vol. 66, no. 6, pp. 674-677, 2018.

[14] Y. Wu, Y. Xu, A. Yang et al., "Comparative in vivo pharmacokinetics study of affeic acid, isoferulic acid and ferulic acid in crude and three different prepared Cimicifuga foetida L," Biomedical Chromatography, vol. 34, no. 9, Article ID e4868, 2020.

[15] Y. Xu, H. Cai, G. Cao et al., "Profiling and analysis of multiple constituents in Baizhu Shaoyao San before and after processing by stir-frying using UHPLC/Q-TOF-MS/MS coupled with multivariate statistical analysis," Journal of Chromatography B, vol. 1083, pp. 110-123, 2018.

[16] H. Y. Fu, Study on the Pharmacokinetics of Euphorbiasteroid, pp. 1-126, Guangzhou University of Chinese Medicine, Guangzhou, China, 2013.

[17] X. Meng, X. Zhao, Z.-M. Long et al., "A sensitive liquid chromatography-mass spectrometry method for simultaneous determination of three diterpenoid esters from $E u$ phorbia lathyris L. in rat plasma," Journal of Pharmaceutical and Biomedical Analysis, vol. 72, pp. 299-305, 2013.

[18] H. Zhu, J. Guan, H. Zhang et al., "Simultaneous determination of ferulic acid, paeoniflorin, and albiflorin in rat plasma by ultra-high performance liquid chromatography with tandem mass spectrometry: application to a pharmacokinetic study of Danggui-Shaoyao-San," Journal of Separation Science, vol. 43, no. 11, pp. 2053-2060, 2020.

[19] N. Percie du Sert, V. Hurst, A. Ahluwalia et al., "The ARRIVE guidelines 2.0: updated guidelines for reporting animal research," British Journal of Pharmacology, vol. 177, no. 16, pp. 3617-3624, 2020.

[20] J. J. Zhu, C. Zhang, Y. Z. Wang, and X. M. Sun, "Study on chemical constituents of petroleum ether Extractant of semen euphorbiae," Journal of Shandong University of Traditional Chinese Medicine, vol. 38, no. 4, pp. 381-391, 2014.

[21] J. J. Zhu, Y. Z. Wang, C. Zhang, B. Yan, and X. M. Sun, "Determination of olein compositions in the petroleum ether extractant of semen euphorbiae by gas chromatogra phymass," Journal of Shandong University of Traditional Chinese Medicine, vol. 37, pp. 438-441, 2013.

[22] FDA, Guidance for Industry, Bioanalytical Method Validation, FDA, Silver Spring, MD, USA, 2001, http://www.fda.gov/ cder/guidance/index.htm.

[23] H. N. Wang, J. Z. Zhang, Y. X. Cui et al., "Chemical comparison of semen euphorbiae and semen euphorbiae pulveratum by UPLC-Q-TOF/MS coupled with multivariate statistical techniques," Journal of Chinese Pharmaceutical Sciences, vol. 29, no. 7, pp. 470-479, 2020.

[24] S. L. Tang, L. L. Zhang, W. J. Huang, H. B. Chen, and J. Y. Zhang, "LC/MS/MS analysis of the metabolites of lathyrane diterpenoids in Caco-2 cells," Journal of Chinese Medicinal Materials, vol. 39, no. 8, pp. 1771-1774, 2016. 